
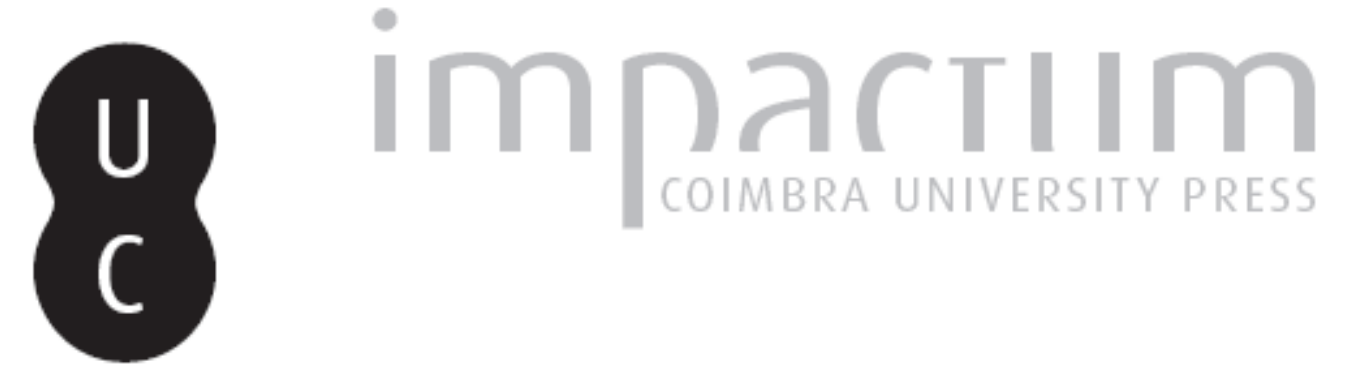

\title{
Estudantes madeirenses na Universidade de Coimbra: entre 1573 e 1730
}

Autor(es): $\quad$ Azevedo e Silva, José Manuel

Publicado por: Imprensa da Universidade de Coimbra

URL persistente:

http://hdl.handle.net/10316.2/42879

DOI:

https://doi.org/10.14195/2183-8925_12_3

Accessed : $\quad$ 26-Apr-2023 15:57:49

A navegação consulta e descarregamento dos títulos inseridos nas Bibliotecas Digitais UC Digitalis, UC Pombalina e UC Impactum, pressupõem a aceitação plena e sem reservas dos Termos e Condições de Uso destas Bibliotecas Digitais, disponíveis em https://digitalis.uc.pt/pt-pt/termos.

Conforme exposto nos referidos Termos e Condições de Uso, o descarregamento de títulos de acesso restrito requer uma licença válida de autorização devendo o utilizador aceder ao(s) documento(s) a partir de um endereço de IP da instituição detentora da supramencionada licença.

Ao utilizador é apenas permitido o descarregamento para uso pessoal, pelo que o emprego do(s) título(s) descarregado(s) para outro fim, designadamente comercial, carece de autorização do respetivo autor ou editor da obra.

Na medida em que todas as obras da UC Digitalis se encontram protegidas pelo Código do Direito de Autor e Direitos Conexos e demais legislação aplicável, toda a cópia, parcial ou total, deste documento, nos casos em que é legalmente admitida, deverá conter ou fazer-se acompanhar por este aviso.

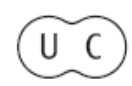




\section{UNIVERSIDADE}

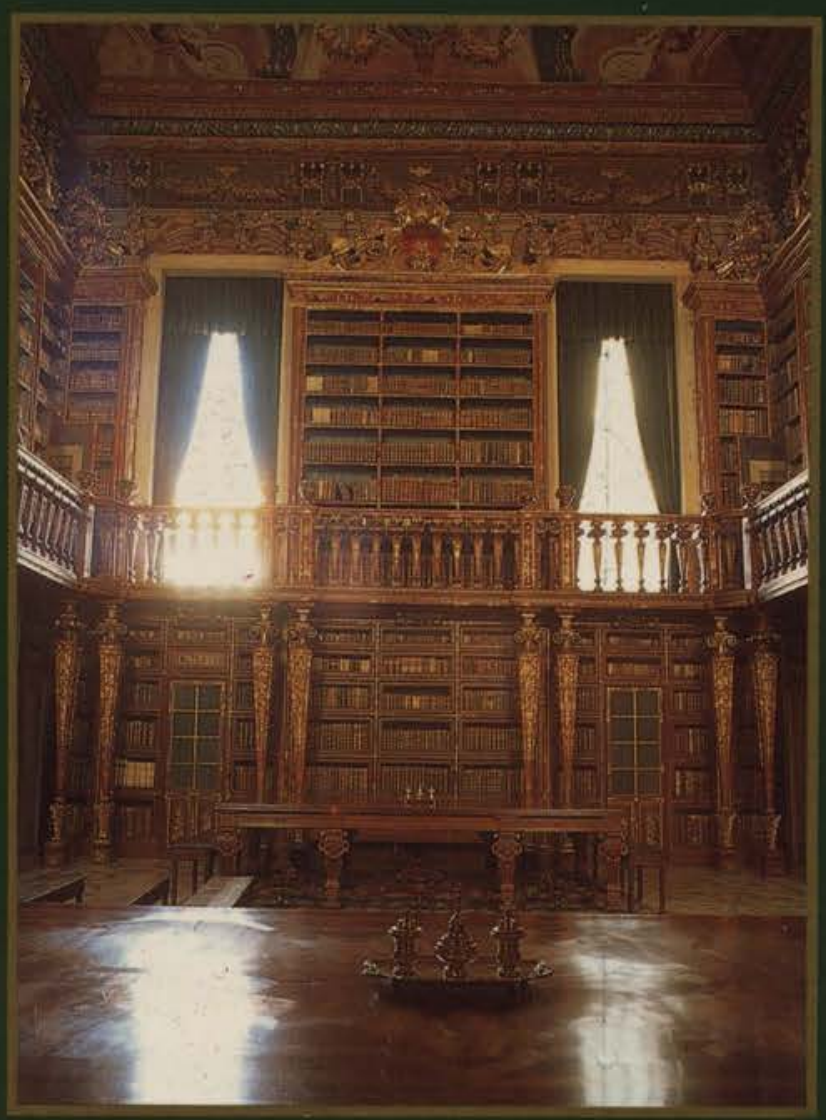

INSTITUTO DE HISTORIA E TEORIA DAS IDEIAS FACULDADE DE LETRAS 


\section{ESTUDANTES MADEIRENSES NA UNIVERSIDADE DE COIMBRA, ENTRE 1573 e 1730}

Tendo residido na cidade do Mondego, durante algum tempo, o sacerdote micaelense, Frei António do Presépio Moniz, falecido cerca de 1930, teve a feliz ideia de inventariar os estudantes açorianos e madeirenses que frequentaram a Universidade de Coimbra, pesquisando pacientemente, nos seus tempos livres, os arquivos desta universidade.

Obteve, assim, uma extensa relação afabetada de 587 estudantes que frequentaram a Universidade de Coimbra, entre 1573 e 1730, a qual contém, além dos nomes, a filiação, o curso, a data da matrícula e o período de frequência neste estabelecimento de ensino superior e outras indicações de bastante interesse para a compreensão da realidade intelectual e cultural e até económica e sociológica das ilhas da Madeira e dos Açores.

A referida relação, que após a morte do padre António do Presépio ficou na posse da sua família, residente na cidade de Ponta Delgada, permite-nos comparar, não só aqueles arquipélagos com o Reino, mas também relacionar as principais ilhas dos referidos arquipélagos entre si, proporcionalmente à população de cada um dos espaços, relativamente ao índice de estudantes que cursaram na Universidade de Coimbra, durante aquele longo período de mais de século e meio.

* Faculdade de Letras da Universidade de Coimbra. 
Geograficamente, os 587 estudantes universitários aparecem-nos assim distribuídos:

Quadro I

\begin{tabular}{|c|c|c|c|}
\hline Ilhas & Número & $\%$ & Média anual \\
\hline Madeira & 274 & 46,7 & 1,73 \\
\hline S. Miguel & 149 & 25,4 & 0,94 \\
\hline Terceira & 108 & 18,4 & 0,68 \\
\hline Faial & 24 & 4 & 0,15 \\
\hline Restantes ilhas açorianas & 32 & 5,5 & 0,2 \\
\hline Totais & 587 & 100 & - \\
\hline
\end{tabular}

Uma lista nominal dos 274 estudantes madeirenses, ordenada alfabeticamente, foi publicada, em 1931, no boletim da Câmara Municipal do Funchal, fundado nesse mesmo ano (1). A partir dessa lista e tendo em conta os nossos objectivos, elaborámos por ordem cronológica, a que apresentamos em anexo e que serve de base a este nosso trabalho.

A distribuição dos referidos estudantes madeirenses por cursos é a seguinte:

Quadro II

\begin{tabular}{|c|c|c|}
\hline Curso & Número & $\%$ \\
\hline Cânones & 187 & 68,2 \\
\hline Teologia & 32 & 11,7 \\
\hline Leis & 24 & 8,7 \\
\hline Leis e Cânones & 17 & 6,2 \\
\hline Medicina & 11 & 4 \\
\hline Leis e Medicina & 1 & 0,4 \\
\hline Medicina e Cânones & 1 & 0,4 \\
\hline Sem indicação de curso & 1 & 0,4 \\
\hline Totais & 274 & 100 \\
\hline
\end{tabular}

(1) Arquivo Histórico da Madeira, vol. I, pp. 145-150, vol. II, pp. 60-64 e 168-172. 
Para podermos comparar as partes com o todo, vejamos agora o quadro dos alunos matriculados na Universidade de Coimbra, de 1573 a 1772:

Quadro III

\begin{tabular}{|c|c|c|c|}
\hline Curso & Número & $\%$ & Média anual \\
\hline Cânones & 237860 & 76,2 & 1189 \\
\hline Leis & 42269 & 13,5 & 211 \\
\hline Medicina & 21842 & 7 & 109 \\
\hline Teologia & 10138 & 3,3 & 51 \\
\hline Totais & 312109 & 100 & 1560 \\
\hline
\end{tabular}

Fonte: A. G. Ribeiro de Vasconcelos, citado por Vitorino Magalhães Godinho, A Estrutura da Antiga Sociedade Portuguesa, 2. ${ }^{\text {a }}$ edição, Lisboa, Arcádia, 1975, p. 252 .

Precisamos ainda de algumas referências demográficas para podermos manejar estes elementos nas suas múltiplas vertentes. Situemo-nos nos finais do século XVI e vejamos a população de cada um dos espaços: o Reino deverá rondar 1.400 .000 habitantes; a Madeira conta cerca de 30.000 (2); os Açores registam 65.000, dos quais 25.000 na ilha de S. Miguel e 23.000 na ilha Terceira ( ${ }^{3}$ ).

Proporcionalmente à população, temos que, se o índice dos alunos madeirenses que, nesse período de tempo, frequentaram a Universidade de Coimbra é muito inferior ao do Reino, ele é bastante superior (quase o dobro) ao dos Açores, o que, em princípio, poderá denotar um maior desafogo económico dos madeirenses em relação aos açorianos, nessa época.

Com efeito, se aos 312.109 alunos que representam o universo estudantil de Coimbra, entre 1573 e 1772, subtrairmos os 587 dos dois arquipélagos atlânticos, ficam-nos 311.622 que, divididos pelos duzentos anos compreendidos entre aquelas balizas cronológicas, nos dá uma média anual de 1.558 alunos matriculados, o que corresponde a pouco mais de um aluno por cada mil habitantes do Reino.

Por outro lado, os 274 estudantes madeirenses matriculados ao longo dos 158 anos a que respeitam dá uma média anual de quase dois alu-

(2) Gaspar Frutuoso, As Saudades da Terra, caps. IX, XV, XVI, XVII e XVIII e nota XIX.

(3) João Marinho dos Santos, Os Açores nos séculos XV e XVI (Dissertação de Doutoramento), Coimbra, 1987, vol. I, p. 136 e ss. 
nos $(1,73)$, o que, tendo em conta a população da ilha, dá a fracção 0,057 por cada mil habitantes, donde nos vem um índice quase vinte vezes $(19,3)$ inferior ao do Reino (entenda-se que os 311.622 alunos atrás referidos respeitam ao Reino, aos restantes espaços ultramarinos e a eventuais alunos estrangeiros, mas pensamos que, nessa época, isso pouco modificará esta relação).

Seguindo o mesmo raciocínio e efectuando idênticas operações matemáticas, temos que, embora $\mathrm{S}$. Miguel apresente um índice superior ao da Terceira e esta também superior ao do Faial e restantes ilhas do arquipélago, os Açores, no seu conjunto, apresentam uma taxa média anual de cerca de dois estudantes matriculados na Universidade de Coimbra, o que, proporcionalmente à sua população, corresponde a cerca de metade em relação à Madeira e, logo, quase quarenta vezes $(36,6)$ inferior ao índice do Reino.

Como explicar tamanhas disparidades?

Parece-nos óbvio que não podemos buscar a explicação apenas no factor económico, embora este não deva desprezar-se. O peso da insularidade está aqui bem patente, mais nos Açores que na Madeira, pois os custos dos transportes e de manutenção eram, então como hoje, mais onerosos para os estudantes insulares em relação aos continentais.

Daí que, por hipótese, se no Reino uma família de classe possidente média podia mandar um filho estudar para Coimbra, na Madeira e nos Açores, mais ainda nestes que naquela, só as famílias gradas e de rendimentos superiores à média poderiam fazer o mesmo.

Passemos a outro tipo de análise. O que é que se estudava na Universidade de Coimbra nos séculos XVI, XVII e XVIII? Quais os cursos existentes e quais os preferidos?

Uma rápida consulta do quadro III dá-nos uma primeira resposta.

Mas ficam por explicar as razões que levavam a população escolar a preferir, de forma inequívoca, a formatura em Cânones $(76,2 \%)$, logo seguida pela de Leis $(13,5 \%)$. É que estes dois cursos habilitavam para o exercício de cargos públicos.

Se assim era, porquê a manifesta preferência de Cânones em relação a Leis?

A escolha é visivelmente determinada pela garantia das saídas profissionais. Com efeito, enquanto que o curso de Cânones habilitava tanto para os cargos da Igreja como para os do Estado e advocacia e magistratura nos dois foros, o curso de Leis habilitava apenas para os cargos do Estado e advocacia e magistratura no foro civil $\left({ }^{4}\right)$.

(4) Cf. Vitorino Magalhães Godinho, A estrutura da antiga sociedade portuguesa, 2. ${ }^{\text {a }}$ edição, Lisboa, Arcádia, 1975, p. 252. 
Vemos, pois, que as ciências jurídicas dominavam largamente a vida universitária coimbrã, com $89,7 \%$ dos estudantes, enquanto que os restantes $10,3 \%$ se distribuíam entre a Medicina (7\%) e a Teologia $(3,3 \%)$, não existindo então qualquer curso de ciências sociais e humanas.

E, se a fraca percentagem de licenciados em Teologia talvez se possa explicar pelo facto de esse número satisfazer as necessidades sociais da função, o mesmo não se pode dizer em relação à igualmente fraca frequência da Medicina que estaria longe de satisfazer as carências sanitárias, devendo procurar-se a explicação na falta de motivações da carreira médica.

Esta é a realidade do universo académico de Coimbra no período em análise. Mas será que o espectro académico dos estudantes madeirenses é coincidente com o todo ou registam-se desvios?

Se passarmos um relance de olhos pela relação que vem em anexo, a partir da qual elaborámos o quadro II, logo nos damos conta de que as ciências jurídicas são ainda mais preferidas, com $94 \%$ dos estudantes madeirenses, contra $89,7 \%$ do todo universitário. Bastante mais preferida é a Teologia, com $11,7 \%$ de madeirenses contra 3,3\% do total. A Medicina é, no caso madeirense, a menos pretendida, com apenas $4 \%$ contra $7 \%$ do universo académico coimbrão.

Um outro problema não pode deixar de ser colocado aqui. Quem é que, nessa época, tinha acesso aos estudos universitários?

Uma vez mais, seguindo a nossa opção metodológica, vamos tentar captar a realidade global para depois a cotejarmos com o caso madeirense.

Uma imagem sociológica, que nos parece bastante fiel, pode colher-se num dos diálogos da Corte na Aldeia, de Francisco Rodrigues Logo. Vale a pena transcrever: - «Têm as escolas, além destes, um bem que favorece esta opinião e é que, de ordinário, os que as buscam, ou são filhos segundos ou terceiros da nobreza do Reino que, por instituição dos morgados de seus avós, ficaram sem heranças e procuraram alcançar a sua polas letras; ou são filhos dos homens honrados e ricos dele, que os podem sustentar com comodidades nos estudos; ou religiosos escolhidos nas suas províncias, por de mais habilidade e confiança para as letras" (5).

Neste caso, parece-nos haver perfeita coincidência dos contornos da imagem sociológica do Reino e da Madeira. Consultando, uma vez mais, a relação dos estudantes madeirenses que apresentamos no final deste trabalho, constatamos que 24 são padres que em Coimbra vêm fazer os cursos de Teologia e Cânones. E há ainda a registar Mestre

(5) Francisco Rodrigues Lobo, Corte na Aldeia e Noites de Inverno, Diálogo 16, 1619, in Vitorino Magalhães Godinho, ob. cit., p. 251. 
Francisco Mondragão, da família do morgadio dos Mondragões da Calheta, que tudo indica tratar-se de um mestre de gramática ligado ao cabido da Sé, a uma paróquia ou a um mosteiro $\left(^{6}\right)$.

Estes eclesiásticos viriam a expensas suas ou seriam subvencionados pelas instituições religiosas a que estavam vinculados? Na segunda hipótese, quais os critérios de selecção?

Como muito bem sustenta Rodrigues Lobo para o Reino, parece-nos que idêntico procedimento se verificava na Madeira. Os eclesiásticos enviados para Coimbra seriam não só escolhidos pelas suas capacidades intelectuais, mas também pelos dotes morais e pela «confiança» que conseguiam inspirar àqueles a quem competia tal decisão.

Outro estrato sociológico, sem dúvida o mais representativo, emergia da nobreza madeirense, ligada às principais "casas" vinculadas. Faça-se uma atenta consulta ao rol dos estudantes madeirenses a que nos vimos referindo. Lá estão os antropónimos das tradicionais «casas" madeirenses: os "Gonçalves", os "Achioli», os "Vasconcelos", os «Atouguia», os já referidos «Mondragão», os «Freitas", os «Aguiar", os "Spínola", os "Câmara", os "Teixeira", os «Ferreira", os "Ornelas" ou "Dornelas", os "Meneses", os «Bettencourt", os «Noronha", os "Abreu», os «Vogado", os «Valdevesso", os "Henriques», os «Aragão", os «Teive», e muitos outros que poderíamos chamar aqui.

O movimento vincular por morgadios e capelas teve, na Madeira, enorme enraizamento, talvez ainda mais acentuado que no Reino. Foi essa a ideia que nos ficou da consulta da vasta documentação do Arquivo Regional da Madeira, ideia que se reforça se tivermos em conta que, à data da sua extinção pela lei de 19 de Maio de 1863, existiam ainda em toda a ilha 659 vínculos que, segundo um relatório oficial de José Silvestre Ribeiro, governador e representante da Madeira no parlamento, entre 1848 e 1858 , representavam dois terços das terras de todo o arquipélago. E dizemos ainda porque a lei pombalina de 9 de Setembo de 1769 suprimiu muitos dos pequenos vínculos e outros foram sendo abolidos por sentença, a rogo dos administradores, alegando que as rendas não davam para satisfazer os encargos ( ${ }^{7}$ ).

Sendo o morgado, por via de regra, administrador e usufrutuário dos bens vinculados, os secundogénitos tinham de tomar uma de três opções: ou entravam na vida religiosa (daí muitos eclesiásticos serem de ascendência nobre), ou seguiam a carreira militar, ou procuravam concluir um curso superior que os habilitasse para o exercício de um cargo público remunerado.

(6) Gaspar Frutuoso, ob. cit., nota XVII, p. 527; Elucidário Madeirense, «Mondragão».

(7) Elucidário Madeirense, «Instituições vinculares» e "Ribeiro (José Silvestre)»; Gaspar Frutuoso, ob. cit., nota XIV, p. 472. 
Para possibilitar a realização da terceira opção, os titulares das mais abastadas "casas" vinculadas destinavam parte das rendas dos vínculos à formação académica dos filhos secundogénitos ou fixavam essa obrigação nas suas disposições testamentárias ou nas cláusulas da instituição do morgadio.

E o caso e Diogo de Teive, originário do Norte de Portugal, que foi para a Madeira a chamamento de seu tio do mesmo nome (aquele que, em 1452, fez contrato com o infante D. Henrique de construir na ilha um engenho de açúcar). Aí casou com Catarina Rodrigues, herdeira de boas fazendas na Ribeira Brava. Em 1531, instituíram morgadio no filho mais velho, Gaspar de Teive, com a obrigação de 20.000 réis anuais (o equivalente a 35 arrobas de açúcar) a seus irmãos, Baltasar e Manuel, até 1540 e 1542, respectivamente, a fim de estes poderem prosseguir os seus estudos em Paris e em Salamanca ( ${ }^{8}$ ).

Outro grupo que procurava nas letras a garantia de vida e a ascensão social era a burguesia mercantil e esse grupo parece-nos estar também representado na nossa relação. Aí se podem ver os «Esteves", os "Moreira", os "Oliveira" e os "Fonseca", entre muitos outros que pela via do casamento, cruzaram os seus nomes com os da nobreza arruinada.

A relação a que temos vindo a fazer referência e que no final se publica permite-nos constatar uma certa regularidade de matrículas de alunos madeirenses na Universidade de Coimbra, entre 1573 e 1730. Embora tenha havido durante esse período de tempo alguns anos em que não chegou qualquer aluno da Madeira a Coimbra, não passou, contudo, nenhuma década sem que se tenham verificado matrículas de estudantes daquela ilha na Academia desta cidade, a uma média de vinte alunos por década, com um mínimo de cinco alunos entre 1660 e 1669 e um máximo de vinte e nove entre 1710 e 1719.

$\mathrm{E}$ antes de 1573 ? Sem que se possa considerar completa a informação de José Pereira da Costa, sabemos, contudo, por seu intermédio, que, durante o século XVI, 20 madeirenses frequentaram a Universidade de Paris, 3 a de Salamanca, outros 3 estudaram em Itália e 61 em Coimbra. Ora, como pela nossa relação se vê que, de 1573 até final do século XVI, se matricularam na Universidade de Coimbra 54 alunos madeirenses, vem-nos que, entre 1537 e 1573, vieram da Madeira para Coimbra 7 universitários $\left({ }^{9}\right)$.

Por outro lado, respigando o livro de Luís de Matos, Les Portugais à L'Université de Paris entre 1500 et 1950 (Coimbra, 1950), detectam-se vinte nomes madeirenses, mas a lista é incompleta, como

(8) Nuno de Vasconcelos Porto, «Madeirenses na Universidade de Paris (1520-1550)", Das Artes e da História da Madeira, n. ${ }^{\circ} 16,1953$, p. 17.

(9) José Pereira da Costa, «O ambiente cultural da Madeira no século XVI", Arquivo Histórico da Madeira, vol. X, pp. 150-197. 
honestamente nos adverte o autor, porque faltam alguns «registos de matrículas" $\left({ }^{10}\right)$.

Os nomes desses madeirenses, alguns dos quais cursaram a Universidade de Paris durante os reitorados de André de Gouveia e de Diogo de Gouveia, o Novo, são os seguintes: Francisco Giraldes, Rodrigo Pires, Marcos Romeiro, Manuel de Teive, Baltasar de Teive, João Baptista, João Ximenes, António Cortês, Francisco Rodrigues, Manuel Mialheiro, Manuel Rodrigues, Francisco de Cristo, Vicente Rodrigues, Cristóvão Rodrigues, António Rodrigues, Fernando Gonçalves da Câmara, Francisco Martins, Luís Gonçalves da Câmara, Leão Henriques e Francisco de Castro (11).

Alguns destes madeirenses distinguiram-se na vida pública e entre a intelectualidade portuguesa da época, nomeadamente como professores da Universidade de Coimbra.

Marcos Romeiro e Francisco de Cristo foram professores de Teologia em Coimbra (12).

Francisco Giraldes, médico, muito versado em latim e grego, aprendeu árabe com Clenardo (13).

Manuel de Teive veio a ser mestre em Artes na capital francesa e beneficiado da sé do Funchal, e seu irmão, Baltasar de Teive, foi promotor do arcebispado de Braga $\left({ }^{14}\right)$.

Francisco Martins parece ter sido professor de Humanidades na Universidade de Salamanca (15).

Leão Henriques, nascido em 1515 na Madeira, era primo de Luís Gonçalves da Câmara, de quem falaremos a seguir e com quem terá ido para Paris, onde ambos estudaram, no Colégio de Santa Bárbara. Ali cursou latim, grego e teologia, mas, como seu primo, veio a formar-se em Teologia na Universidade de Coimbra. Em 30 de Abril de 1546, entrou na Companhia de Jesus e veio a ser reitor do Colégio dos Jesuítas em Coimbra, até 1556. Foi professor e primeiro reitor da Universidade de Évora, inaugurada em 1 de Novembro de 1559 (16).

Luís Gonçalves da Câmara, segundo filho do quarto capitão do Funchal, depois de ter estudado latim, grego, hebraico e teologia em Paris, formou-se em Teologia na Universidade de Coimbra e parece ter chegado a ser escolhido para professor, cargo de que não chegou a tomar posse. Em 1547, foi feito reitor do Colégio dos Jesuítas de Coimbra e, mais tarde, foi nomeado por Inácio de Loiola reitor do Colégio

(10) Nuno Vasconcelos Porto, ob. cit., pp. 15-19.

(11) Ibidem.

(12) Ibidem.

(13) Ibidem

(14) Ibidem

(15) Ibidem

(16) Ibidem. 
de Roma. De regresso à pátria, foi investido do encargo de educador do futuro rei D. Sebastião e, em 1566, passou a ser também seu confessor. Por influência sua junto do rei, seu irmão, Martim Gonçalves da Câmara, também jesuíta e doutor em Teologia, foi nomeado reitor da Universidade de Coimbra, em 21 de Junho de 1563, tendo depois obtido o cargo de escrivão da puridade e, em seguida, ascendido a secretário de Estado, passando a ter grande autoridade no governo do Reino $\left({ }^{17}\right)$.

$\mathrm{Na}$ lista de estudantes madeirense que apresentamos no final, também se detectam algumas figuras públicas e intelectuais, de que destacamos Henrique Henriques de Noronha que frequentou a Universidade de Coimbra entre 1682 e 1684 e onde se formou em Cânones. Historiador e genealogista, escreveu as seguintes obras, ligadas à história da Madeira: Nobiliário genealógico das famílias que pasarão a viver a ésta Ilha da Madeira...; Memorias sobre a creação e augmento do Estado Ecclesiastico na Ilha da Madeira...; Memorias seculares e eclesiasticas para a composição da historia da Diocese do Funchal (18).

À medida que fomos avançando na elaboração deste trabalho, uma questão se nos foi impondo e é esta: os estudos preparatórios de acesso à universidade eram ministrados na Madeira ou no exterior? E, se no exterior, onde, no Reino ou no estrangeiro?

A vasta documentação a que temos tido acesso não nos deixa quaisquer dúvidas de que os primeiros candidatos madeirenses a seminaristas e a universitários não tinham, no interior da ilha, estruturas pedagógicas capazes de os preparar para entrar no seminário ou na universidade. Essa preparação tinha, pois, de ser diligenciada no Reino ou no estrangeiro, consoante as conveniências e as possibilidades de cada um.

É o caso dos irmãos Manuel e Baltasar de Teive, de quem já falámos, os quais, ainda de tenra idade, seguiram para Paris, onde frequentaram o Colégio de Santa Bárbara e só depois os vamos encontrar na Universidade de Salamanca ${ }^{\left({ }^{19}\right)}$.

Idêntico percurso tiveram Luís Gonçalves da Câmara e seu primo, Leão Henriques, que, depois de terem estudado latim, grego e teologia no Colégio de Santa Bárbara, em Paris, vieram a graduar-se em Teologia, na Universidade de Coimbra (20).

Deve notar-se que, por volta de 1520 , o português Diogo Gouveia, o Velho, é nomeado director do Colégio de Santa Bárbara de Paris, tendo então conseguido de D. João III a instituição de cerca de cin-

(17) Dicionário de História de Portugal, "Câmara (Luís e Martim Gonçalves)».

(18) Gilda França Vieira e António Aragão de Freitas, Madeira. Investigação Bibliográfica, Funchal, Centro de Apoio de Ciências Históricas, 1981, p. 289.

(19) Nuno de Vasconcelos Porto, ob. cit., pp. 15-19.

(20) Ibidem. 
quenta bolsas de estudo anuais para que portugueses pudessem frequentar o seu colégio (21).

E aqueles que não puderam sair da ilha, que possibilidades tinham de instruir-se, nos primeiros séculos da colonização?

Sabe-se que as estruturas religiosas rapidamente se organizaram. Alguns franciscanos acompanharam Zarco e outros foram chegando depois. Cerca de 1430 foram criadas as primeiras paróquias e outras se lhes seguiram, acompanhando o ritmo do povoamento do arquipélago. $\mathrm{E}$ os párocos e religiosos, além do ensino catequético podiam ensinar também a ler e a escrever e até ministrar a iniciação ao latim e à gramática. Mas de modo algum este tipo de ensino habilitava ao ingresso no ensino superior.

Não significa isto que o poder central não se preocupasse com as questões do ensino nas ilhas atlânticas. $\mathrm{O}$ foral novo dado por $\mathrm{D}$. Manuel à cidade do Funchal e às vilas de Ponta do Sol e da Calheta, datado de 6 de Agosto de 1515, texto que veio a ser adoptado no foral novo dado a Machico e a Santa Cruz, em 15 de Dezembro desse mesmo ano, estatui «que sejam isentos do pagamento de dízima os livros de estudantes ou de Igreja que não sejam para vender» (22).

Também o poder municipal participou nas questões do ensino, porquanto, nas despesas da Câmara do Funchal do ano de 1550, aparece o pagamento de 4.000 réis ao mestre de gramática $\left({ }^{23}\right)$.

Com a criação da diocese do Funchal, em 1514, passa a existir entre os beneficiados da sé o cargo de mestre-escola com a côngrua anual de 8.000 réis, sucessivamente aumentada, visto que, em 1595 , era de 80.000 réis. O primeiro a exercer esse cargo foi João Rodrigues Bório, cargo que parece ter exercido cumulativamente no Mosteiro de Nossa Senhora da Conceição, das freiras de Santa Clara, tendo-lhe sucedido no referido cargo Conçalo Martins (24).

Abrem-se, pois, novas possibilidades de ensino na Madeira, mas, ainda assim, duvidamos que fossem suficientes para preparar integralmente os candidatos ao ingresso nos seminários ou nas universidades.

Tais condições, a nosso ver, só serão satisfeitas com a fundação do Colégio dos Jesuítas do Funchal, em 1570, com aulas de latim, teologia, filosofia e retórica, e do Seminário do Funchal, criado por carta régia de 20 de Setembro de 1566, mas cuja instauração efectiva só veio a acontecer por volta de $1580(25)$.

(21) Ibidem.

(22) Treslado authentico do Foral da cidade do Funchal, da villa da Ponta do Sol e da Villa Nova da Calheta, in Gaspar Frutuoso, ob. cit., nota XVI, pp. 494-504.

(23) Arquivo Regional da Madeira, Vereações (1550), Livro 1309, fls. 120-127v.

(24) Gaspar Frutuoso, ob. cit., pp. 185 e 574. Cf. Arquivo Histórico da Madeira, vol. V, pp. 106-109.

(25) Gaspar Frutuoso, ob. cit., nota XXX, pp. 738-742; Elucidário Madeirense, 
Antes destas datas, os madeirenses que optavam pela vida clerical tinham de ingressar nos seminários do Reino, junto dos quais, ou em outras instituições religiosas, fariam os estudos preparatórios, com destaque para o Seminário de Braga, no qual, entre 1501 e 1544, foram ordenados 43 sacerdotes provenientes da Madeira (26).

«Seminário» e «Jesuítas»; Cf. Abel A. da Silva, «Seminário do Funchal. Algumas notas para a sua história», Das Artes e da História da Madeira, n. ${ }^{\circ} 34-1964$, pp. 1-12.

(26) Eugénio de Andrea da Cunha e Freitas, «Alguns madeirenses que receberam ordens em Braga (1501-1544)», Das Artes e da História da Madeira, n. ${ }^{\circ} 36$, 1966, pp. 28-29. 
RELAÇÃO DOS ESTUDANTES MADEIRENSES QUE FREQUENTARAM A UNIVERSIDADE DE COIMBRA ENTRE 1573 E 1730

\begin{tabular}{|c|c|c|}
\hline Nome & Curso & Período \\
\hline João Gomes & Teologia & 1573 \\
\hline Gaspar Afonso & Cânones & 1573 \\
\hline António Gonçalves & Teologia & 1573 \\
\hline Luís Gaspar (Bacharel) & Leis & $1573-1574$ \\
\hline Sebastião Luís & Cânones & $1573-1574$ \\
\hline Gonçalo Esteves & Cânones & $1573-1578$ \\
\hline Francisco Correia & Teologia & $1573-1579$ \\
\hline Manuel Afonso & Teologia & $1573-1580$ \\
\hline Tomé Alves Usadamar & Leis & $1577-1578$ \\
\hline Miguel Achioli & Cânones & $1577-1581$ \\
\hline Francisco Gonçalves & Leis & $1577-1583$ \\
\hline Rui de Mendonça e Vasconcelos & Leis e Cânones & $1577-1584$ \\
\hline Baltazar Pardo de Ornelas & Cânones & $1578-1583$ \\
\hline Gaspar Leite & Leis & $1578-1584$ \\
\hline Álvaro Vaz da Costa (Bacharel) & Leis & $1578-1584$ \\
\hline António de Lemos & Cânones & $1578-1588$ \\
\hline Garcia de Motagrã & Leis & 1579 \\
\hline Pedro Agrela & Cânones & $1579-1580$ \\
\hline Agostinho de Atouguia & Cânones & $1579-1586$ \\
\hline Álvaro Meireles & Cânones & 1581 \\
\hline Henrique Pereira & Leis & $1581-1586$ \\
\hline António Aguiar & Teologia & $1581-1589$ \\
\hline Manuel Rodrigues Pedreira & Leis & $1583-1589$ \\
\hline João Rodrigues Pestana & Leis & $1585-1587$ \\
\hline Francisco de Spínola & Leis e Cânones & $1585-1591$ \\
\hline João Berte de Oliveira (Bacharel) & Leis & $1586-1592$ \\
\hline Gonçalo Rodrigues Minhoto & Cânones & $1586-1595$ \\
\hline Francisco Rodrigues & Leis & $1587-1591$ \\
\hline João Rodrigues Mondragão & Cânones & $1588-1591$ \\
\hline Bartolomeu do Vale & Teologia & $1588-1593$ \\
\hline Bartolomeu Pacheco de Aragão & Cânones & $1588-1593$ \\
\hline Simão Achioli & Leis e Cânones & $1588-1594$ \\
\hline Rui Dias & Teologia & $1588-1594$ \\
\hline Manuel Rodrigues Pimentel & Cânones & $1588-1595$ \\
\hline João Rodrigues Cabral & Cânones & $1588-1598$ \\
\hline Francisco Mondragão (Mestre) & Teologia & $1588-1599$ \\
\hline Diogo Lira & Cânones & $1589-1591$ \\
\hline Manuel de Almeida Pereira & Cânones & $1589-1595$ \\
\hline João Drumond & Teologia & $1589-1595$ \\
\hline João Rodrigues de Freitas & Leis & $1589-1599$ \\
\hline Manuel Rodrigues & Cânones & $1591-1592$ \\
\hline Bartolomeu de Mondragão & Cânones & $1591-1594$ \\
\hline Luís Spínola & Cânones & $1591-1599$ \\
\hline Lucas da Silva & Cânones & $1591-1601$ \\
\hline Jorge de Andrade Correia & Cânones & $1592-1599$ \\
\hline
\end{tabular}




\begin{tabular}{|c|c|c|}
\hline Nome & Curso & Período \\
\hline Bartolomeu Cardoso & Teologia & 1593 \\
\hline Manuel da Silva & Leis & 1593-1594 \\
\hline Jerónimo Coelho & Cânones & 1594 \\
\hline António de Aguiar & Teologia & 1594 \\
\hline João Cordomil & Teologia & $1594-1598$ \\
\hline Luís Dias & Medicina & $1594-1601$ \\
\hline António Gonçalves & Teologia & $1595-1598$ \\
\hline Paulo Nunes & Cânones & $1598-1599$ \\
\hline Jorge Freire & Cânones & $1600-1603$ \\
\hline Sebastião Nogueira Gama & Teologia & $1601-1604$ \\
\hline Fernão Carneiro & Cânones e Medicina & $1601-1615$ \\
\hline Manuel Rodrigues de Figueiredo & Cânones & $1602-1604$ \\
\hline Manuel Vogado & Não indicado & $1602-1608$ \\
\hline Francisco de Aguiar & Cânones & $1603-1611$ \\
\hline Manuel Pinto & Leis e Cânones & $1603-1612$ \\
\hline Cristóvão Rodrigues & Teologia & 1607 \\
\hline António Vogado & Teologia & $1607-1610$ \\
\hline Valentim Fernandes & Cânones & $1607-1613$ \\
\hline Bento de Matos & Cânones & $1607-1614$ \\
\hline Pedro Gonçalves & Cânones & $1607-1614$ \\
\hline António Rodrigues Rocha & Teologia & 1608 \\
\hline Aleixo Caldeira & Cânones & $1608-1617$ \\
\hline Gaspar Lopes de Morais & Teologia & 1609 \\
\hline Luís Gonçalves Pinheiro & Leis e Cânones & $1609-1615$ \\
\hline João Dias & Cânones & $1610-1612$ \\
\hline Luís Gonçalves & Cânones & $1610-1613$ \\
\hline Fernão Favila de Vasconcelos & Leis e Medicina & $1611-1619$ \\
\hline Braz de Seixas & Cânones & 1612 \\
\hline Francisco do Cabo & Cânones & 1612 \\
\hline Pedro Paulo de Sousa & Cânones & 1613-1614 \\
\hline Pedro Gonçalves & Cânones & $1614-1619$ \\
\hline Pedro Moreira & Cânones & $1614-1619$ \\
\hline Sebastião Pereira & Cânones & $1616-1617$ \\
\hline João Spníola & Cânones & $1617-1620$ \\
\hline Manuel de Barros & Leis & $1621-1629$ \\
\hline Domingos de Figueiredo & Cânones & $1622-1625$ \\
\hline António Francisco & Cânones & $1623-1625$ \\
\hline Lucas Gonçalves & Teologia & $1623-1626$ \\
\hline Gregório Gomes & Leis & $1623-1627$ \\
\hline Jorge da Câmara & Cânones & $1623-1630$ \\
\hline Simão Gonçalves da Câmara & Cânones & $1623-1630$ \\
\hline Belchior Teixeira Tavares & Cânones & $1624-1628$ \\
\hline Guilherme Fradique (Padre) & Teologia & $1624-1628$ \\
\hline Francisco Azevedo de Mendonça & Leis & $1624-1629$ \\
\hline Martim Dória de Vasconcelos & Cânones & $1624-1629$ \\
\hline
\end{tabular}




\begin{tabular}{|c|c|c|}
\hline Nome & Curso & Período \\
\hline João de Moura Rolim & Cânones & $1625-1627$ \\
\hline António Ferreira & Cânones & $1625-1628$ \\
\hline Felipe Vogado & Leis e Cânones & $1625-1631$ \\
\hline António Furtado de Mendonça & Cânones & 1626 \\
\hline Jerónimo Vieira & Cânones & $1626-1631$ \\
\hline Manuel da Silveira & Leis e Cânones & $1627-1633$ \\
\hline Simão da Gama & Medicina & $1627-1633$ \\
\hline Simão Gonçalves Cidrão & Cânones & $1627-1634$ \\
\hline António da Costa Cardoso & Teologia & $1628-1632$ \\
\hline Francisco de Castro & Cânones & $1628-1634$ \\
\hline Simão Machado de Miranda & Leis e Cânones & $1628-1638$ \\
\hline Feliciano Martins & Cânones & 1629 \\
\hline André do Couto & Cânones & $1629-1635$ \\
\hline Sebastião do Canto & Leis e Cânones & $1629-1636$ \\
\hline Braz Ferreira & Leis & 1630 \\
\hline Manuel Ferreira Neto (Padre) & Cânones & $1630-1636$ \\
\hline Pedro de Carvalho & Cânones & $1631-1632$ \\
\hline Pedro Teixeira de Vasconcelos & Cânones & $1631-1634$ \\
\hline Manuel Freire de Andrade & Cânones & $1631-1636$ \\
\hline Manuel Dias Saldanha & Teologia & $1632-1636$ \\
\hline João de Araújo (Padre) & Cânones & $1632-1639$ \\
\hline Bento Teixeira de Saldanha & Leis & $1633-1640$ \\
\hline Manuel de Carvalho (Padre) & Cânones & $1633-1640$ \\
\hline Manuel Ribeiro Neto & Cânones & $1633-1640$ \\
\hline João Gomes de Abreu & Cânones & 1634 \\
\hline Manuel Ferraz da Silva & Cânones & $1634-1635$ \\
\hline Braz de Freitas & Cânones & $1634-1639$ \\
\hline Roque Fernandes Teles & Leis e Cânones & $1634-1641$ \\
\hline Rui Fernandes Teles & Cânones & $1635-1637$ \\
\hline António Pacheco & Leis & $1635-1640$ \\
\hline Francisco de Figueiredo & Leis & 1636 \\
\hline Manuel de Andrade & Cânones & $1637-1638$ \\
\hline Manuel Dias Ferreira (Padre) & Teologia & $1637-1640$ \\
\hline Lucas de Vasconcelos & Cânones & $1638-1644$ \\
\hline António Veloso de Lira (Padre) & Teologia & $1641-1643$ \\
\hline Manuel Dias de Lira & Teologia & $1641-1643$ \\
\hline João de Sousa & Cânones & $1641-1648$ \\
\hline José Pinheiro Taveira & Cânones & $1641-1652$ \\
\hline António do Couto (Padre) & Teologia & $1642-1644$ \\
\hline Francisco Aguiar de Gouveia & Cânones & $1642-1657$ \\
\hline Manuel Lopes da Silva & Teologia & $1643-1644$ \\
\hline Manuel de Sousa Benevides & Teologia & $1644-1645$ \\
\hline Pedro da Costa Arruda & Leis & $1644-1645$ \\
\hline Manuel Denis da Silva & Cânones & $1646-1653$ \\
\hline Manuel de Sousa & Cânones & $1647-1648$ \\
\hline
\end{tabular}




\begin{tabular}{|c|c|c|}
\hline Nome & Curso & Período \\
\hline José de Araújo & Cânones & $1647-1649$ \\
\hline Manuel de Araújo de Sousa & Cânones & $1648-1653$ \\
\hline Lourenço de Matos Coutinho & Cânones & $1648-1654$ \\
\hline Domingos de Carvalho & Leis & $1648-1659$ \\
\hline Pedro Milanês & Cânones & $1649-1654$ \\
\hline Diogo Mendes Duro & Cânones & $1650-1656$ \\
\hline João Ornelas de Gamboa & Cânones & $1651-1656$ \\
\hline Lucas de Freitas Aragão & Leis e Cânones & $1651-1656$ \\
\hline Bento Pacheco & Cânones & 1652 \\
\hline Pedro Peres & Cânones & $1652-1653$ \\
\hline Fernão Gomes & Cânones & 1653 \\
\hline Luís Fernandes de Sousa & Cânones & $1654-1655$ \\
\hline Manuel da Rocha & Cânones & $1655-1656$ \\
\hline Manuel da Fonseca & Cânones & $1655-1656$ \\
\hline Luís Fernandes de Oliveira & Cânones & $1655-1660$ \\
\hline Marcos da Fonseca Cerveira & Cânones & $1655-1661$ \\
\hline Francisco Moniz de Menezes & Cânones & $1656-1663$ \\
\hline Luís Telo de Meneses & Cânones & $1656-1663$ \\
\hline Manuel Maciel da Fonseca & Leis e Cânones & $1657-1661$ \\
\hline António de França e Câmara & Cânones & $1658-1661$ \\
\hline Manuel de Carvalho Valdavesso & Leis e Cânones & $1658-1662$ \\
\hline Gaspar de Valdavesso & Leis e Cânones & $1658-1664$ \\
\hline Lucas de Freitas Branco (Padre) & Leis e Cânones & $1659-1660$ \\
\hline António de Freitas Branco & Cânones & $1659-1664$ \\
\hline António Spínola & Medicina & $1661-1666$ \\
\hline António Valente de Sampaio & Cânones & $1663-1670$ \\
\hline João Deniz da Silva & Cânones & 1668 \\
\hline António Moniz de Menezes & Cânones & 1668 \\
\hline Antão Manuel Teles & Cânones & $1669-1706$ \\
\hline António Gonçalves de Freitas (Padre) & Cânones & $1672-1678$ \\
\hline Francisco Cabral da Câmara & Cânones & $1672-1678$ \\
\hline António Pereira da Silva & Cânones & $1672-1680$ \\
\hline João Gomes de Castro e Câmara & Cânones & $1672-1680$ \\
\hline Pedro Correia & Cânones & $1674-1679$ \\
\hline Pedro de Bettencourt Henriques & Cânones & $1676-1683$ \\
\hline Francisco Álvares Cardoso (Padre) & Cânones & $1677-1679$ \\
\hline Cristóvão de Lira e Sousa & Cânones & $1677-1682$ \\
\hline João Ferreira Gabriel (Padre) & Cânones & $1677-1683$ \\
\hline Zenóbio de Médicis (Padre, Dom) & Teologia & $1677-1684$ \\
\hline António da Câmara Leme & Cânones & $1677-1686$ \\
\hline Manuel Pereira de Castro (Padre) & Teologia & $1679-1683$ \\
\hline Valentim da Mota Andrade (Padre) & Cânones & $1679-1689$ \\
\hline António Correia Barbosa & Cânones & $1680-1686$ \\
\hline Manuel de Oliveira & Cânones & $1680-1687$ \\
\hline José Fernandes Tavares & Medicina & $1681-1686$ \\
\hline António Correia Bettencourt & Cânones & $1681-1687$ \\
\hline
\end{tabular}




\begin{tabular}{|c|c|c|}
\hline Nome & Curso & Período \\
\hline Tomás Henriques Pais & Leis e Cânones & $1681-1687$ \\
\hline Henrique Henriques de Noronha & Cânones & $1682-1684$ \\
\hline Pedro Álvares Usel & Cânones & $1682-1688$ \\
\hline Francisco da Costa & Cânones & 1683 \\
\hline António Correia de Bettencourt & Cânones & $1683-1685$ \\
\hline Marcelino Correia & Cânones & $1684-1686$ \\
\hline Estêvão de Abreu Barreto & Cânones & $1684-1691$ \\
\hline Francisco da Costa Jardim & Cânones & $1684-1691$ \\
\hline Timóteo Coutinho Simões & Medicina & $1685-1698$ \\
\hline António de Aguiar e Sá & Cânones & $1685-1694$ \\
\hline António Lopes da Silva & Cânones & $1686-1692$ \\
\hline Manuel Gomes Jardim & Cânones & $1686-1693$ \\
\hline Manuel Lopes Caldeira & Leis e Cânones & $1686-1693$ \\
\hline Manuel Lopes da Silva & Cânones & $1686-1693$ \\
\hline Francisco de Vasconcelos Coutinho & Cânones & $1687-1695$ \\
\hline Feliciano Fernandes & Cânones & $1688-1693$ \\
\hline Manuel da Silva & Cânones & $1690-1698$ \\
\hline Pedro Cervantes & Cânones & $1691-1697$ \\
\hline António Vieira & Cânones & $1693-1699$ \\
\hline Luís da Silva de Brito & Cânones & $1693-1699$ \\
\hline Marcos da Fonseca Cerveira & Cânones & $1693-1699$ \\
\hline Felipe do Vale & Cânones & $1695-1699$ \\
\hline António Rodrigues Correia & Cânones & $1695-1700$ \\
\hline Manuel de Freitas & Medicina & $1695-1700$ \\
\hline Agostinho de Ornelas de Vasconcelos & Cânones & $1698-1702$ \\
\hline António Vieira de Leandro & Cânones & 1699 \\
\hline Francisco de Andrade Pereira & Cânones & $1700-1707$ \\
\hline Lourenço da Cruz Macedo & Cânones & $1700-1707$ \\
\hline Domingos Leite & Cânones & $1702-1708$ \\
\hline Silveste Lopes Barreto & Cânones & $1702-1708$ \\
\hline Manuel Fernandes Mondim (Padre) & Cânones & $1702-1709$ \\
\hline André Pereira de Aguiar & Cânones & $1703-1709$ \\
\hline Manuel de Oliveira de Aguiar & Cânones & $1704-1705$ \\
\hline Atanásio Caldeira & Cânones & $1704-1709$ \\
\hline José da Costa & Cânones & $1704-1710$ \\
\hline Jorge de França Andrade & Cânones & $1705-1713$ \\
\hline Domingos de Sá Martins & Cânones & $1706-1713$ \\
\hline Manuel da Costa & Cânones & $1708-1715$ \\
\hline Manuel Álvares de Castro & Medicina & $1709-1711$ \\
\hline Manuel Teixeira Brasão & Cânones & $1709-1714$ \\
\hline Manuel dos Passos & Cânones & $1709-1715$ \\
\hline Pedro de Sousa e Aragão & Cânones & $1709-1715$ \\
\hline António Fernandes Barradas & Cânones & $1709-1716$ \\
\hline Inácio Barbosa & Cânones & $1709-1716$ \\
\hline João da Silva Seixas (Padre) & Cânones & $1709-1716$ \\
\hline Felipe de Ocanha Vieira (Padre) & Cânones & $1709-1717$ \\
\hline Manuel Lopes de Andrade & Cânones & $1710-1713$ \\
\hline
\end{tabular}




\begin{tabular}{|c|c|c|}
\hline Nome & Curso & Período \\
\hline João Rodrigues de Oliva & Cânones & $1710-1716$ \\
\hline Inácio Pereira Pimenta & Cânones & $1710-1717$ \\
\hline António de Freitas Sousa & Leis & 1711 \\
\hline José Fernandes Tavares & Medicina & $1711-1717$ \\
\hline António Monteiro de Miranda (Padre) & Teologia & $1711-1719$ \\
\hline Simão Moniz (Padre) & Cânones & $1712-1717$ \\
\hline António Pereira da Silva & Cânones & $1712-1719$ \\
\hline Manuel de Faria Abreu & Cânones & $1712-1719$ \\
\hline Diogo Lopes Caldeira (Padre) & Cânones & $1712-1720$ \\
\hline Manuel Gonçalves Rocha & Cânones & 1713-1719 \\
\hline Manuel Vogado Souto-Maior & Cânones & 1713-1719 \\
\hline Sebastião Vogado Souto-Maior & Cânones & 1713-1719 \\
\hline Francisco de França e Andrade & Cânones & 1714-1719 \\
\hline Luís de Freitas Ferraz & Cânones & $1714-1719$ \\
\hline Francisco Bettencourt Herédia & Cânones & $1714-1720$ \\
\hline João de França e Andrade & Cânones & $1714-1720$ \\
\hline Tomé Vieira e Barreto (Padre) & Cânones & $1715-1721$ \\
\hline João Baptista Spínola (Padre) & Cânones & $1716-1721$ \\
\hline Julião de França Coutinho & Cânones & $1716-1621$ \\
\hline Manuel Marques de Moura (Padre) & Cânones & $1716-1722$ \\
\hline Francisco Luís de Miranda & Leis & 1717 \\
\hline António de Faria Severim & Cânones & $1717-1721$ \\
\hline Francisco Bettencourt Correia & Cânones & $1717-1722$ \\
\hline Pedro Correia de Albuquerque & Cânones & $1717-1723$ \\
\hline Francisco Luís de Miranda & Cânones & $1718-1727$ \\
\hline Nicolau Biard de Ossuna & Cânones & $1719-1723$ \\
\hline Caetano de Caires & Cânones & $1719-1724$ \\
\hline Francisco Xavier Aranha (Padre) & Cânones & $1719-1725$ \\
\hline Nicolau Francisco da Silva & Cânones & $1720-1723$ \\
\hline José Caetano de Bettencourt & Cânones & $1720-1726$ \\
\hline Amaro de França Uzel & Medicina & $1723-1727$ \\
\hline Ambrósio de França e Ataíde & Cânones & $1723-1728$ \\
\hline João José de Sá (Dom) & Cânones & $1723-1728$ \\
\hline Francisco Pinto de Abreu & Cânones & $1724-1729$ \\
\hline Francisco de Lira & Cânones & $1724-1730$ \\
\hline António Ferreira Duarte & Cânones & $1726-1730$ \\
\hline António Simeão Lobo e Matos & Cânones & $1726-1730$ \\
\hline João Henrique de Aragão & Cânones & $1726-1730$ \\
\hline Francisco Fernandes Coelho & Cânones & $1727-1729$ \\
\hline Fr. Henrique dos Serafins (Padre) & Cânones & $1728-1729$ \\
\hline António Caetano de Sousa & Cânones & $1728-1730$ \\
\hline António Pereira Borges & Cânones & $1728-1730$ \\
\hline José Caetano Ribeiro & Cânones & $1728-1730$ \\
\hline Pedro Pereira da Silva & Cânones & $1728-1730$ \\
\hline António da Costa Campos Leitão & Cânones & 1729 \\
\hline Sebastião de Teives & Cânones & Sem data \\
\hline
\end{tabular}

Fonte: «Relação do padre António do Presépio Moniz», Arquivo Histórico da Madeira, vol. I, pp. 145-150 e vol. II, pp. 60-64 e 168-172. 